\title{
Understanding Students' Engagement with Personalised Feedback Messages
}

\author{
Hamideh Iraj* \\ School of Information Technology \& \\ Mathematical Sciences \\ University of South Australia \\ Adelaide, SA, Australia \\ hamideh.iraj@mymail.unisa.edu.au
}

\author{
Anthea Fudge \\ UniSA College \\ University of South Australia \\ Adelaide, SA, Australia \\ anthea.fudge@unisa.edu.au
}

\author{
Margaret Faulkner \\ Business School \\ University of South Australia \\ Adelaide, SA, Australia \\ margaret.faulkner@unisa.edu.au
}

\author{
Abelardo Pardo \\ Division of Information Technology, \\ Engineering and the Environment \\ University of South Australia \\ Adelaide, SA, Australia \\ abelardo.pardo@unisa.edu.au
}

\author{
Vitomir Kovanović \\ School of Education and Teaching \\ Innovation Unit \\ University of South Australia \\ Adelaide, SA, Australia \\ vitomir.kovanovic@unisa.edu.au
}

\section{KEYWORDS}

Feedback, Learning Analytics, Higher Education, Feedback Gap, Data-Driven Approaches tion learning. However, recent changes - such as increased class sizes and socio-economic diversity of the student population - challenged the provision of effective student feedback. Although the use of educational technology for personalised feedback to diverse students has gained traction, the feedback gap still exists: educators wonder which students respond to feedback and which do not. In this study, a set of trackable Call to Action (CTA) links was embedded in two sets of feedback messages focusing on students' time management, with the goal of (1) examining the association between feedback engagement and course success and (2), to predict students' reaction to provided feedback. We also conducted two focus groups to further examine students' perception of provided feedback messages. Our results revealed that early engagement with the feedback was associated with higher chances of succeeding in the course. Likewise, previous engagement with feedback was highly predictive of students' engagement in the future, and also that certain student sub-populations, (e.g., female students), were more likely to engage than others. Such insight enables instructors to ask "why" questions, improve feedback processes and narrow the feedback gap. Practical implications of our findings are further discussed.

\section{CCS CONCEPTS}

- Information systems $\rightarrow$ Clustering and classification; • Applied computing $\rightarrow$ E-learning; Distance learning;

\footnotetext{
${ }^{*}$ Corresponding author

Permission to make digital or hard copies of all or part of this work for personal or classroom use is granted without fee provided that copies are not made or distributed for profit or commercial advantage and that copies bear this notice and the full citation on the first page. Copyrights for components of this work owned by others than the author(s) must be honored. Abstracting with credit is permitted. To copy otherwise, or republish, to post on servers or to redistribute to lists, requires prior specific permission and/or a fee. Request permissions from permissions@acm.org.

LAK '20, March 23-27, 2020, Frankfurt, Germany

(C) 2020 Copyright held by the owner/author(s). Publication rights licensed to ACM ACM ISBN 978-1-4503-7712-6/20/03...\$15.00

https://doi.org/10.1145/3375462.3375527
}

\section{ACM Reference Format:}

Hamideh Iraj, Anthea Fudge, Margaret Faulkner, Abelardo Pardo, and Vitomir Kovanović. 2020. Understanding Students' Engagement with Personalised Feedback Messages. In Proceedings of the 10th International Conference on Learning Analytics and Knowledge (LAK '20), March 23-27, 2020, Frankfurt, Germany. ACM, New York, NY, USA, 10 pages. https://doi.org/10.1145/ 3375462.3375527

\section{INTRODUCTION}

Over the past several decades, there has been a continual shift in the higher education landscape; Universities are in the midst of a growing global competitive market, driven by the massification and consumerisation of higher education. The impact of such competition for students and reduced government funding has altered the way universities operate [19]. The associated reductions in government funding in higher education have called for more efficient and cost-effective operations. This process has led to the introduction of larger class sizes to aid the profitability of operations [9]. However, larger classes are associated with a wide range of unfavourable results such as poor feedback [23], higher dissatisfaction [21], fewer opportunities for monitoring student learning progression [29] and lower academic performance [38].

To solve the problems stemming from large classes, universities recognised the need for designing new educational systems and processes and re-engineered their educational procedures, taking advantage of technological advances to serve students' needs and meet their expectations. This trend has increased flexible education models such as online programs [1]. Although these programs offer a flexible curriculum for students, mitigating their dependency to time and place, the lack of on-campus attendance translates into lost opportunities for being in a learning community and receiving feedback from instructors [71]. Research has shown that online students have high rates of drop-out [51] due to feelings of isolation and 
lack of interactivity [37]. Hence, being able to give students quality feedback may help students to have a better learning experience.

Although improving student university experience is a complex and challenging problem, one of the key factors affecting student learning and success is feedback. This finding is part of a large network of evidence emerging from dozens of studies pointing to the power of feedback in education [30]. Yet, feedback is only effective if students take it up and act upon it [76]. In order to do so, students need to be able to understand the feedback, develop the capacities to judge their work, manage their emotions upon receiving feedback and finally, act upon on the given information [14]. These steps highlight the role of the feedback recipience process [74] in the effectiveness of feedback. A review of feedback literature revealed that what students, rather than educators, perceive as useful is what helps them to learn $[55,75,76]$. However, several of the important factors that affect the recipience of technology-mediated feedback has been currently underexplored. In particular, the role of feedback actionability received little attention so for, despite its known importance on shaping students' perception of feedback and its effectiveness in improving learning outcomes.

This paper aims to investigate how actionability affects the recipience of technology-mediated feedback messages. To examine the effect of actionability, we draw on the large body of research from marketing where message actionability was extensively explored and link to the current literature on feedback in education. Specifically, this paper will examine the inclusion of "Call to Action (CTA)" clickable links in feedback emails around time management and its effect on feedback recipience. The insights of the present study provide important insights for the course instructors and designers around the development of feedback processes in a way that maximises recipience, and ultimately improve student learning experience and success.

\section{BACKGROUND}

\subsection{Towards actionable educational feedback}

Over the years, two main paradigms of feedback have been conceptualised [14]. Originally, the key component of feedback was the provision of relevant information. In their seminal paper, Hattie and Timperley [30, p. 81] defined feedback as "information provided by an agent (e.g., teacher, peer, book, parent, self, experience) regarding aspects of one's performance or understanding”. They differentiated among feed up (where am I going?), feed back (how am I going?), and feed forward (where to next?), highlighting the need for addressing these questions to provide efficient feedback. In other words, good feedback shows the learner's process towards a learning goal based on specific standards and prior performance, and also points to the possible improvement scenarios [30].

Another important differentiation of feedback is around the level of feedback. In this regard, Hattie and Timperley [30] differentiate between (1) task-level feedback (2) process-level feedback, and (3) self-regulatory feedback. The goal of task-level feedback, also known as confirmatory or disconfirmatory feedback, is to provide feedback for a particular learning task, with respect to its requirements. In contrast, process-level feedback focuses on specific learning strategies and learning processes required to complete the task. Finally, feedback on self-regulatory level focuses on enabling students to monitor and regulate their own learning [11, 72]. This includes supporting students in setting or adjusting their goals, managing time and study environment, selecting appropriate learning strategies, and evaluating the effectiveness of adopted study strategies [72].

While the early notion of feedback emphasised the provision of relevant information, the new paradigm of feedback focuses on supporting students' and teachers' actions. Feedback goes beyond potentially useful information and is seen as a process to change student behaviour [14]. This focus on actions has been emphasised by Boud and Molloy [8, p. 205] who defined feedback as " $a$ process whereby learners obtain information about their work to appreciate the similarities and differences between the appropriate standards for any given work, and the qualities of the work itself, to generate improved work". Acting on feedback was also considered by Shute [62, p. 153] who views feedback as "information communicated to the learner that is intended to modify his or her thinking or behaviour to improve learning". In this regard, the ideas of feedback recipience [74] and feedback literacy [14] emerged as a part of the new paradigm, highlighting the role of students in understanding the feedback and turning it into action.

\subsection{Aspects of feedback actionability}

2.2.1 Feedback recipience and feedback gap. The recipience of feedback concerns with how students understand, interpret and act upon feedback they receive [32]. Feedback by itself is insufficient for improving learning and student success $[30,74]$. For example, students might not fully understand received feedback, and might required need help to fully comprehend it [48]. This discrepancy between the potential and actual use of feedback has been referred to as "feedback gap" [17, 19] or "feedback paradox" [77]. To narrow the gap, researchers have investigated how students receive and interpret feedback and which behavioural and emotional hurdles hold students back from making the best use of it [54, 74, 75]. There has been a surge of recent interest in studying feedback recipience $[12,13,33,55,74,76]$, with most of the studies investigating the learner's satisfaction $[47,68,75]$ and perceptions $[18,39,58,69]$, while only a few considered learners' behaviours [32, 55, 74] or characteristics [70]. Feedback recipience is an active and mutual interaction among learners and educators; learners share the responsibility of learning with the educators and contribute to making feedback work [74].

There is a consensus in the education literature that feedback recipience is a complex, multi-dimensional and contingent topic [62, 74]. While feedback can enhance learning performance, this is not consistent for every context and for all students [19, 30, 36, 74]. Some instances of feedback do not affect learning at all and may even debilitate performance [36], negative perceptions and confusion [32], especially in technology-mediated settings [22]. Due to the complexity and contingency of feedback on personal situations, the effectiveness of the process is increased when the process is personalised [42, 50]. Given the strong evidence of the effects of individual student differences on their learning success, previous research highlighted the need for considering their effects on feedback recipience $[7,74]$. For example, highly developed self-regulated learning (SRL) [72] skills in large extent determine how students utilise the provided feedback to alter their study approaches [11]. Finally, the perception of feedback is further influenced by learners' goals and study habits [17], as well as different personal and demographic characteristics [70]. 
2.2.2 Feedback literacy. As indicated by Kluger and DeNisi [36], communicating feedback is the starting point in the feedback process, rather than its ending point. Students need to understand the feedback and come up with plans to act on the feedback and improve the quality of their work. These skills are encapsulated in the term "feedback literacy" [14] which is essential in enabling students to make effective use of the feedback they receive. The four aspects of feedback literacy include (1) understanding the role and importance of feedback in their learning process, (2) judging the quality of their work through internal or external feedback, (3) managing their emotions and overcoming negative feelings if they received critical feedback, and (4) acting on feedback, i.e. improving the quality of their work or learning process [14]. Although essential, feedback literacy is often taken for granted in universities. In many cases, it is assumed that merely giving high-quality feedback will produce strong positive effects on students learning and success [74]. However, this statement is not necessarily true, as students often lack the literacy and skills required to make use of feedback to improve their learning [14].

\subsection{Technology-mediated feedback in education}

Over the last few decades, important changes within higher education rendered the provision of high-quality, personalised feedback much more challenging [47]. First of all, due to the democratisation of higher education and support for non-traditional and underprivileged students, there has been an increase in the number and diversity of university students [53]. The number of fee-paying international students has also soared globally to compensate for the declining government funds, further increasing the diversity of student body who have different learning needs and feedback expectations [4, 6, 34]. In these circumstances, universities started devising plans to meet students' demands and give all students equal chances for academic success, regardless of their background and socio-economic status [2, 17, 34, 45, 61, 79]. Finally, there has been a substantial increase in class sizes and part-time teaching appointments, which limited the ability of instructors to track student progress and tailor feedback to their needs and expectations [9, 57, 58]. Not surprisingly, these changes resulted in a widespread dissatisfaction with feedback among university students [19, 47, 55].

To overcome the feedback challenges, technological advances came in with the promise of providing feedback at scale [17, 50]. A rich source of information about students' learning processes is contained in educational databases and learning management systems so educators and researchers can take advantage of the data deluge to turn raw data into actionable feedback and help students in their learning process $[43,50]$. Over time, different technology-supported feedback systems have been developed and implemented at universities across the world. Examples include Course Signals [5], E2Coach [44], Competency Map [25], SRES [42] and OnTask [41, 49]. Technology-supported feedback systems open new opportunities for providing feedback to students, and had proven to be effective for engaging students $[17,41]$, boosting students' satisfaction [50] and improving outcomes [17, 50]. However, to be effective, these systems require a delicate combination of course design structure, instructors' domain knowledge, and automated process for feedback provision at scale [50], typically using email or SMS messages, or student dashboards.

\subsection{Actionability of technology-mediated educational feedback}

While the importance of actionability has been acknowledged in the feedback literature [62], the provision of actionable feedback using different educational technologies has been very limited. These include different forms of educational dashboards and email messages, which often did not explicitly include clear actionable information. As shown by Gašević et al. [22] not only that the poor design of such systems is not contributing to student success, it can actually be harmful to their overall learning and promote ineffective learning strategies. Even when potentially-useful information is delivered to students in a technology-mediated manner, the importance of feedback recipience and actionability is often neglected or underestimated [74]. For instance, Corrin and De Barba [16] revealed that many students could not interpret their progress shown in educational dashboards, mostly due to confusion and subsequent inaction, making them unable to benefit from the provided feedback. One of the early attempts to collect students' action on dashboards relied on self-reported surveys and interviews [15]. Although these research methods might provide useful insights in understanding students' actions, they are not scalable and they cannot show patterns in bigger cohorts of students.

There have been several efforts in the past to make the technologymediated feedback more actionable. In this regard, one common approach is to provide students with direct hyperlinks to specific learning resources or activities. For example, Herodotou et al. [31] provided students with direct links to preparation materials in their feedback messages, while Tempelaar et al. [67] provided links to videos on the Khan Academy website. Another example is the dashboard developed by Broos et al. [10], where a button labelled "Okay, what now?" was provided to students to inform them about suggested next learning activity, such as suggestions for additional learning content. However, to the best of our knowledge, there is very little empirical evidence of the effectiveness of such actionable links on students' learning experience and success. As a result of this gap in the research literature, two research questions remain to be unanswered: first, what is the effect of feedback actionability on academic performance and second, what is the effect of individual student differences in responding to feedback. Although, studentlevel differences proved to be effective in response to feedback $[11,30,48,74]$ and researchers agree on "one size does not fit all" in provision of feedback [66], this topic has not been investigated quantitatively so far.

\subsection{Activity tracking in Digital marketing}

While tracking the activity on provided actionable links has not been much researched in technology-mediated feedback domain, it has been highly prominent in digital marketing fields. In fact, systematic collection and examination of user engagement with provided email advertisement represents a critical component of digital marketing campaigns and necessary to assess their effectiveness $[28,60,63,80]$. A common approach for tracking user behaviour is the use of personalised email messages with trackable CTAs hyperlinks that can reveal how users engage with provided content [26]. In this method, users' behaviour in each marketing campaign is monitored through data-driven mechanisms, and the success of the campaign is measured in terms of clicks that gradually engage users with their products and services. A click on a 
CTA button redirects users to a specific page on the company website [27], which is designed to further engage the user in the desired manner (e.g., buying an item, downloading a brochure, installing a demo version of the software) $[3,52]$. This data-driven approach is used extensively in digital marketing and allows marketers to design campaigns and measure and analyse the clicks data quantitatively [27]

\section{RESEARCH QUESTIONS}

As shown in the previous section, the provision of feedback as information is inadequate for learning since the goal of feedback is to support students in making decisions [74]. Typical systems stop at providing the information and do not consider the processes required to turn feedback into changes or actions [14]. One of the problems in the feedback process is that educators do not know which students are acting on feedback due to the lack of any mechanism to track students' use of feedback [17, 59, 78]. The inability to measure the effects of feedback prevents researchers and educators to delve deep into feedback and customising the feedback at a deeper level. John Wanamaker, a prominent figure in marketing once said: "Half the money I spend on advertising is wasted; the trouble is I don't know which half" [24, p. 18]. The same holds true for education; Educators put a lot of time and effort to give feedback to students $[73$, p. 6], yet they have little idea on how students engage with that feedback. Which students even read their feedback, and more importantly, which students act, or do not act, on the provided feedback? [35]. In this regard, a data-driven approach for understanding students' responses to provided feedback has tremendous opportunities to narrow the feedback gap by making the provided feedback messages more actionable.

In this paper, we explore the actionability of personalised feedback messages provided to students in a technology-mediated manner. Specifically, we explore the effects of utilising CTA structure of email communication that is popular in marketing [26, p. 25-27] to examine students engagement with provided feedback messages. As a result, the current paper addresses three research questions:

- RQ1. What is the association between student engagement with feedback and their academic success?

- RQ2. What student populations, as captured by demographic and engagement measures are engaging with the provided feedback messages?

- RQ3. How do students perceive actionability of provided feedback, as expressed through CTA clickable links?

In this study, we will explore these questions in the context of feedback provision and we will investigate the effect on students time management in two summative quizzes. By exploring student engagement with provided CTA links, we can help educators and educational designers to understand the nuances of recipience to feedback in technology-mediated settings and ultimately narrow the feedback gap. Finally, exploration of these questions also opens new doors for researchers to do a fine-grained analysis of student engagement data at the CTA level that is currently underexplored in the learning analytics literature.
Hi David,

Well done to review a few key resources for Bioscience! Quiz 2 is coming up soon and it's time to try the practice quiz. This practice will be very helpful for you to get the best marks that you can. Just like before, feel free to attempt the practice quiz multiple times to properly prepare and be ready for Quiz 2 .

Now that you are aware of the specifics for Quiz 2, you might want to also revisit key resources on the course page that will ensure proper preparation to really do well and maximise your marks.

Any questions or worries please get in contact.

Take Practice Quiz for Quiz 2!

Kind regards,

\section{Figure 1: A Sample Email}

\section{METHODS}

\subsection{Study data}

4.1.1 Course structure. An introductory science course offered was selected for the current study. The course is part of the university's one-year foundation studies and two-year diploma programs, which are university's alternative pathways towards bachelor's degrees. These programs are designed as university pathways to help students without the necessary qualifications for undergraduate studies. The course covered the basics of life sciences and living organisms as well as the fundamentals of the scientific method. It had no prerequisites so students could enrol into the course regardless of their educational background, even without completing high school. Like in other similar courses, the class sizes were large and consisting of a wide range of students from diverse backgrounds. Due to the challenging nature of these courses, they represent a suitable arena for examining the provision of scalable feedback and support to students and to measure the effects of their success. Failure to support these students effectively may discourage them from pursuing STEM professions, especially for women, minorities and other under-represented groups [44]. Prior to starting the current research, the required ethics clearance has been granted by the university internal review board. Participants were 218 students enrolled in the current course at 2019 summer term at a large public research university in Australia.

To examine feedback recipience, in this study we focused on providing students with feedback on their progress with two quiz activities during the ten weeks of the course. Quiz 1 was due the end of week five, while quiz 2 was due the end of week ten. Every week, we provided students with a personalised message that provides them with suggested learning activities for completing each quiz, and also the feedback on their activity during the previous week. For example, during week 1, we instructed students to explore learning resources relevant for completing the first quiz. Then the following week, we would either remind students that they have not accessed those materials (if they have not clicked on the link provided in the email) or congratulate them on completing the previous week's activity (if they clicked on the provided email link). 
The goal of the provided messages was to support students with managing their time and promote spaced learning over an extended period, which had been associated with better academic success [7] Finally, we should note that due to unforeseen circumstances, the second message for quiz 2 (Week 7) was not sent. As a result, there was no feedback provided in Week 7 of the course.

4.1.2 Implementation offeedback interventions. Feedback messages were delivered to students each week using the OnTask [49] platform, which used records of student engagement inside Moodle Learning Management System (LMS). The OnTask platform offers the possibility of sending customised emails to students in a course, based on their engagement in previous weeks. The platform also offers a generic HTML editor that was used to prepare personalised student messages and insert the HTML links into email messages. To enable better formatting of email messages, we styled HTML links using inline CSS styles, so they appear as button rather than simple HTML links. A sample feedback email is shown in Figure 1. At the end of each message, we created a call to action which will make it easy for students to engage in a particular learning activity [49]. Finally, students who did not complete a given learning task also received a reminder email five days later.

We created the call to action by adding a new URL resource [46] which redirects students to an LMS page. We did so to distinguish access to learning resources directly from within LMS, and access originating from the feedback messages. To achieve that, the created URL resources were not shown anywhere within the LMS and were thus, only available to students through the links within their feedback messages. In this manner, activity tracking for each student is simple to achieve using a combination of already-existing functionalities of OnTask and Moodle LMS.

\subsection{Data collection and analysis}

In this study, we collected student clicks on CTA links as simple binary variables. We also collected students' final course grades, as well as a list of demographic variables. The summary of collected demographics is shown on Table 1.

To answer RQ1 and RQ2, we used simple logistic regressions, which is a widely used method for predicting binary outcome variables due to its high predictive power and intuitive interpretation [20]. To answer RQ1, we used clicks on each of the five CTAs as predictors of students' final course grade. To answer RQ2, we used demographic variables listed in Table 1 to predict student engagement with the feedback in the following week. In addition, each subsequent week included feedback engagement from previous weeks as binary predictors. For each model, all the predictors were put in the generalised linear model using glm function in R statistical package [65]. For model evaluation, accuracy was calculated using base R and the area under the ROC plot (AUC) was calculated using PROC package [56]. Finally, to answer RQ3, we conducted a focus group interview with students' to gather their perceptions of the provided feedback messages. Students responses in focus groups were then analysed thematically to identify prominent themes in their responses. The whole process was repeated until no more themes were derived, as suggested by Lacey and Luff [40].
Table 1: Descriptive Statistics for Predictors

\begin{tabular}{llrr}
\hline Variable & Value & Frequency & Percentage \\
\hline Study Program & Diploma & 80 & $36 \%$ \\
& Foundation & 138 & $63 \%$ \\
Attendance & Full-time & 203 & $93 \%$ \\
& Part-time & 15 & $6 \%$ \\
Gender & Male & 75 & $34 \%$ \\
& Female & 143 & $65 \%$ \\
Mature age & Yes & 37 & $16 \%$ \\
& No & 181 & $83 \%$ \\
English at home & Yes & 182 & $83 \%$ \\
& No & 36 & $16 \%$ \\
Admission basis & Secondary education & 44 & $20 \%$ \\
& VET & 29 & $13 \%$ \\
& Mature-age & 8 & $3 \%$ \\
& Other & 137 & $62 \%$ \\
Previous attainment & Secondary education & 112 & $51 \%$ \\
& Some college & 12 & $5 \%$ \\
& VET ${ }^{*}$ course & 68 & $31 \%$ \\
& Nothing & 26 & $11 \%$ \\
\hline
\end{tabular}

* VET stands for Vocational Education and Training

\section{RESULTS}

\subsection{RQ1: The association between feedback engagement and course completion}

To examine the association between weekly engagement and course completion, a logistic regression model with students' weekly feedback engagement as predictors and course completion was conducted. Overall, the model achieved classification accuracy of $68 \%$, with F score of 0.64 and AUC (Area under the curve) of 0.71 (Table 2). Interestingly, from all predictors, the only two that were significant were first emails for both quiz 1 and quiz 2. Students who engaged with Week 1 email were 2.25 times more likely to pass the course, while students who engaged with Week 6 email were 4.14 times more likely to pass the course.

\subsection{RQ2: Association between student demographics and feedback engagement}

We also examined how different student populations engage with feedback. We conducted nine logistic regression models predicting

Table 2: Logistic regression results for predicting passing the course with weekly feedback engagement.

\begin{tabular}{lrrrc}
\hline Predictor & OR & SE & Stat. & $p$ \\
\hline Week 1 engagement (Quiz 1) & $\mathbf{2 . 2 5}$ & $\mathbf{0 . 3 7}$ & 2.22 & $\mathbf{0 . 0 3}^{*}$ \\
Week 2 engagement (Quiz 1) & 0.82 & 0.48 & -0.41 & 0.68 \\
Week 3 engagement (Quiz 1) & 0.92 & 0.45 & -0.20 & 0.84 \\
Week 4 engagement (Quiz 1) & 1.68 & 0.58 & 0.90 & 0.37 \\
Week 5 engagement (Quiz 1) & 1.42 & 0.40 & 0.88 & 0.38 \\
Week 6 engagement (Quiz 2) & $\mathbf{4 . 1 4}$ & $\mathbf{0 . 5 7}$ & $\mathbf{2 . 5 0}$ & $\mathbf{0 . 0 1 *}$ \\
Week 8 engagement (Quiz 2) & 1.97 & 0.58 & 1.18 & 0.24 \\
Week 9 engagement (Quiz 2) & 0.52 & 0.72 & -0.91 & 0.36 \\
Week 10 engagement (Quiz 2) & 0.67 & 0.78 & -0.51 & 0.61 \\
\hline
\end{tabular}


Table 3: Results of weekly logistic regression models.

\begin{tabular}{lrrr}
\hline Outcome variable & Accuracy & F1 score & AUC \\
\hline Week 1 engagement (Quiz 1) & 0.63 & 0.55 & 0.68 \\
Week 2 engagement (Quiz 1) & 0.69 & 0.43 & 0.83 \\
Week 3 engagement (Quiz 1) & 0.68 & 0.27 & 0.74 \\
Week 4 engagement (Quiz 1) & 0.71 & 0.22 & 0.78 \\
Week 5 engagement (Quiz 1) & 0.73 & 0.09 & 0.79 \\
Week 6 engagement (Quiz 2) & 0.75 & 0.31 & 0.81 \\
Week 8 engagement (Quiz 2) & 0.77 & 0.29 & 0.84 \\
Week 9 engagement (Quiz 2) & 0.81 & 0.13 & 0.88 \\
Week 10 engagement (Quiz 2) & 1.00 & 0.20 & 1.00 \\
\hline
\end{tabular}

students' weekly engagement with feedback using a set of student demographics and their previous feedback engagement as predictors. As shown in Table 3, all models achieved high accuracy, ranging from $63 \%$ for Week 1, to $100 \%$ for Week 10 . However, F1 scores, which are robust measures of the quality of model prediction, are ranging from 0.55 for Week 1, to 0.09 or Week 5. Except for the anomaly for Week 9, F1 scores are decreasing for engagement with individual quizzes, which are highest for Weeks 1 and 6.

Looking at Table 4, we see that the strongest predictor across all models was Week 1 engagement, which was a significant predictor of feedback engagement for Weeks 2-4. Week 2 engagement was less strongly associated with other week's engagement, only reaching significance for Week 7 engagement. Students who engaged with Week 2 emails were 5 times more likely to engage with Week 7 emails. Also, students' engagement in Weeks 8 and 9 was significantly predicted by their past feedback engagement. Students who engaged with feedback in Week 3 were 3.26 times more likely to engage with Week 8 feedback that students who did not engage with Week 3 feedback. Similarly, students who engaged with Week 4 feedback were around six times more likely to engage with both feedback in Week 8 and 9. Finally, students who engaged with Week 7 feedback were 6 and 14 times more likely to engage with Week 8 and Week 9 feedback, respectively.

Looking at the demographics predictors, we also see some significant associations between student demographics and their engagement with the feedback messages. Most notably, female students were more than 2 times more likely to engage with feedback in Week 1 and Week 7, while non-native English speakers were 4.5 times more likely to engage with Week 5 feedback. Finally, mature students and students who did not have any previous attainment were about 4 times less likely to engage with Week 8 feedback messages. Finally, to provide more insights into the nature of engagement of the identified student populations, we also looked in more detail at some of the most significant group differences, which are shown in Table 5.

\subsection{RQ3: The students' perception of CTAs in personalised feedback messages}

Finally, to examine students perception of provided actionable CTA links in their feedback messages, we conducted two focus groups with eight and five students, respectively. Students expressed a wide variety of opinions towards the course and the feedback they received. The following themes emerged in the focus group: the challenging nature of the course, feedback message as a reminder and the role of links in engaging with the course.
5.3.1 Challenging nature of the course. Students found the course challenging and hard, especially those who had not done any chemistry or biology in high-school. They mentioned that attending the lectures and tutorials helped them in understanding the contents of the course. Interacting with fellow students also helped struggling students to learn in this course.

5.3.2 Email messages as reminders. Personalised feedback emails helped students to evaluate their progress towards the course and get back on track in case they were falling behind. One student said: "It made sure I got things done because I'm a big procrastinator." Another student described her feelings when opening the emails: "So when I got them I was like, oh this is overwhelming and then I was like, no And then I just kinda deleted them [respondents laugh]. But like a few of 'em were good. A few of them would pop up and be like, you got an email from the co-ordinator, which was helpful. And every time that came up I was like, oh this must be important". However the feeling changed after acting on the feedback: "once you like clicked on it you're like, okay I've done it, it's done."

5.3.3 The role of links in engaging with the course. Students mentioned that links made the emails easy to understand and act upon. One student said: "I guess if you're lazy you just click it and you know where it is [laughs] so easier". Another student mentioned "They kinda help because they take you straight there instead of having to go through." Another student described the role of links in her own words: "You're just reading then oh you know exactly what she meant."

\section{DISCUSSION}

The first research question examined the relationship between engaging with each feedback CTAs and passing the course. According to RQ1 results (Table 2), acting upon the email (via clicking on the first CTA) was correlated with passing the course. This implies that early responses to feedback messages can predict how well students will complete the course. Our results indicate that students who engage with the feedback early in the course have higher chances of finishing the course successfully. This might be explained by the point that acting on feedback messages nudged students to engage early with the course and study regularly throughout the semester [41]. Furthermore, early engagement creates more time for spaced learning, interleaving and other learning strategies that are associated with higher retention in the long-run[7].

The second research question examined the association between students' demographics and feedback engagement, to identify groups of students who have specific challenges with feedback engagement. In our study, the association of feedback engagement with student demographics was sporadic, without any consistent association over time (Table 4). The only pattern belonged to female students, who were more likely to engage in Week 2 and Week 7, for non-English speakers for Week 5, and Mature students for week 8 . Interestingly, the findings for female students are aligned with the previous research by Turner and Gibbs [70] who suggested that females students are more likely to act on feedback. However, whether this phenomenon represents a signal or noise or any intricacies of the course design affect these associations would require further examination.

Finally, the third research question focused on students perception of feedback messages which included CTA links. As discussed 
Table 4: Odds ratios for nine logistic regression models predicting feedback weekly engagement using demographic and feedback engagement predictors. Boldface represents significance on $p<.05$ level.

\begin{tabular}{|c|c|c|c|c|c|c|c|c|c|}
\hline \multirow[b]{2}{*}{ Predictor variable } & \multicolumn{9}{|c|}{ Outcome variable } \\
\hline & $\begin{array}{r}\text { Week } 1 \\
\text { Feedback } \\
\text { Eng. }\end{array}$ & $\begin{array}{r}\text { Week } 2 \\
\text { Feedback } \\
\text { Eng. }\end{array}$ & $\begin{array}{r}\text { Week } 3 \\
\text { Feedback } \\
\text { Eng. }\end{array}$ & $\begin{array}{r}\text { Week } 4 \\
\text { Feedback } \\
\text { Eng. }\end{array}$ & $\begin{array}{r}\text { Week } 5 \\
\text { Feedback } \\
\text { Eng. }\end{array}$ & $\begin{array}{r}\text { Week } 6 \\
\text { Feedback } \\
\text { Eng. }\end{array}$ & $\begin{array}{r}\text { Week } 8 \\
\text { Feedback } \\
\text { Eng. }\end{array}$ & $\begin{array}{r}\text { Week } 9 \\
\text { Feedback } \\
\text { Eng. }\end{array}$ & $\begin{array}{r}\text { Week } 10 \\
\text { Feedback } \\
\text { Eng. }\end{array}$ \\
\hline Admission basis $=$ Mature age & 2.05 & 0.27 & 1.48 & 0.95 & 9.97 & 0.30 & 0.59 & 9.22 & 1.00 \\
\hline Admission basis $=$ Other & 0.49 & 0.04 & 0.23 & 1.51 & 1.64 & 0.93 & 3.97 & 1.03 & 1.00 \\
\hline Admission basis = VET & 0.65 & 1.31 & 1.54 & 3.15 & 1.74 & 1.04 & 0.68 & NA & 1.00 \\
\hline Attendance $=$ Part-time & 0.89 & 0.74 & 0.77 & 0.88 & NA & 0.66 & 2.12 & 0.44 & 1.00 \\
\hline Gender $=$ Female & 2.35 & 0.55 & 1.23 & 2.59 & 2.43 & 2.78 & 1.07 & 0.55 & 1.00 \\
\hline English at home $=\mathrm{No}$ & 0.70 & 1.36 & 2.34 & 1.65 & 4.58 & 1.26 & 1.14 & 1.18 & 1.00 \\
\hline Mature $=$ No & 0.67 & 0.46 & 1.32 & 0.44 & 1.09 & 0.89 & 0.26 & 0.73 & 1.00 \\
\hline Previous attainment $=$ Nothing & 0.62 & 1.21 & 0.78 & 0.74 & 0.76 & 3.48 & 0.17 & 0.29 & 1.00 \\
\hline Previous attainment $=$ Some college & 0.69 & 0.07 & 1.37 & NA & NA & 1.91 & NA & NA & 1.00 \\
\hline Previous attainment $=$ VET course & 1.56 & 0.61 & 0.64 & 0.27 & 0.56 & 1.01 & 0.79 & 3.05 & 1.00 \\
\hline Program = Foundation & 0.78 & 18.61 & 2.83 & 0.43 & 0.51 & 1.16 & 0.64 & 0.55 & 1.00 \\
\hline Week 1 Feedback Engagement & & 27.75 & 2.86 & 5.33 & 2.81 & 2.00 & 2.12 & 0.47 & 1.00 \\
\hline Week 2 Feedback Engagement & & & 2.16 & 0.34 & 0.57 & 5.62 & 0.56 & 0.73 & 1.00 \\
\hline Week 3 Feedback Engagement & & & & 1.50 & 0.62 & 1.86 & 3.26 & 0.79 & 1.00 \\
\hline Week 4 Feedback Engagement & & & & & 2.06 & 0.97 & 6.31 & 6.59 & 1.00 \\
\hline Week 5 Feedback Engagement & & & & & & 1.24 & 2.84 & NA & 1.00 \\
\hline Week 6 Feedback Engagement & & & & & & & 6.38 & 14.34 & 1.00 \\
\hline Week 8 Feedback Engagement & & & & & & & & 1.02 & 1.00 \\
\hline Week 9 Feedback Engagement & & & & & & & & & 1.00 \\
\hline
\end{tabular}

Baseline for Admission basis = Secondary education

Baseline for Previous attainment $=$ Secondary education

in Section 5.3, three themes were observed in the focus group. Two of the themes existed in the research literature. Introductory science courses have always been challenging for students [44]. Also, the previous research in customised feedback messages revealed that feedback messages helped students track their progress [50]. However, the third emergent theme was new to education and provided novel insights on students responses to feedback messages containing a CTA. The value of making messages easy and saving users' time is well-recognised in digital marketing [64]

\section{LIMITATIONS}

The present study has some limitations. First, the patterns observed in this study originate from a small student cohort and as such much not be generalisable to other learning contexts. Each course is a unique learning experience and student engagement is a function of many educational (such as teaching method, the structure of the course) and non-educational factors (such as the timing of the emails, appropriate subject lines and possible technical issues). Future research in this area will unfold which patterns are observed in different situations. Second, the associations found in this study have correlational nature and causal relationships could not be inferred from an observational study like the current research paper. Finally, we recognise the limitations of the proxy used for student feedback in this study and acknowledge that clicking a CTA link does not necessarily mean that action was taken nor that learning has happened. Human learning is inherently complex and no measure can capture this complexity perfectly. However, the measures of student engagement with the provided feedback represent useful proxy measures that enable us to improve our understanding of human learning and interaction with the feedback.

\section{CONCLUSION}

The present study has two main contributions. First of all, to the best of our knowledge the present study is the first one to empirically examine students engagement with technology-mediated feedback in online settings. While previous studies examined students' perceptions of provided feedback, we tracked student engagement with the provided feedback and looked at its association with their course completion and demographic factors. Secondly, this study outlines the methodology for using OnTask and Moodle platforms to run similar analyses in the future. The proposed approach does not require expensive URL tracking functionalities that do not exist in current learning platforms and uses simple and handy functionalities that are familiar to most online educators. While this study is the first step towards understanding of students' engagement with provided feedback, we hope that in the future, similar studies will be done to provide further insights into the complexities of feedback provision in technology-mediated settings.

From the standpoint of improving understanding of feedback provision in technology-mediated settings, our findings reveal that early engagement is highly indicative of students course completion. This pattern is aligned with the existing literature around selfregulated learning skills and the role of proper time management in student learning $[11,72]$. One potential opportunity of monitoring feedback engagement using the proposed methodology is early intervention for supporting students who are falling behind in their studies. In this way, monitoring student reaction to provided 
Table 5: Student engagement with feedback messages for different groups of students that showed significant differences in logistic regression models.

\begin{tabular}{|c|c|c|c|c|c|}
\hline \multirow[b]{2}{*}{ Feedback Message } & \multicolumn{2}{|c|}{ Group } & \multirow[b]{2}{*}{ Total Emails Sent } & \multicolumn{2}{|c|}{ Engagement } \\
\hline & Variable & Value & & Total CTA Clicks & Percentage \\
\hline \multirow[t]{2}{*}{ Week 1 (Quiz 1) } & Gender & Male & 75 & 31 & 41 \\
\hline & & Female & 143 & 82 & 57 \\
\hline \multirow[t]{2}{*}{ Week 2 (Quiz 1) } & Week 1 Engaged & No & 105 & 3 & 3 \\
\hline & & Yes & 113 & 43 & 38 \\
\hline \multirow[t]{2}{*}{ Week 3 (Quiz 1) } & Week 1 Engaged & No & 105 & 9 & 9 \\
\hline & & Yes & 113 & 30 & 27 \\
\hline \multirow[t]{2}{*}{ Week 4 (Quiz 1) } & Week 1 Engaged & No & 105 & 6 & 6 \\
\hline & & Yes & 113 & 23 & 20 \\
\hline \multirow[t]{2}{*}{ Week 5 (Quiz 1) } & English at home & Yes & 182 & 6 & 3 \\
\hline & & No & 36 & 4 & 11 \\
\hline \multirow[t]{4}{*}{ Week 6 (Quiz 2) } & Gender & Male & 71 & 9 & 13 \\
\hline & & Female & 127 & 37 & 29 \\
\hline & Week 2 Engaged & No & 153 & 22 & 14 \\
\hline & & Yes & 45 & 24 & 53 \\
\hline \multirow[t]{12}{*}{ Week 8 (Quiz 2) } & Mature & Yes & 32 & 10 & 31 \\
\hline & & No & 166 & 26 & 16 \\
\hline & Previous attainment & Secondary Education & 103 & 21 & 20 \\
\hline & & Some College & 10 & 0 & 0 \\
\hline & Previous attainment & VET Course & 64 & 12 & 19 \\
\hline & & Nothing & 21 & 3 & 14 \\
\hline & Week 3 Engaged & No & 160 & 23 & 14 \\
\hline & & Yes & 38 & 13 & 34 \\
\hline & Week 4 Engaged & No & 169 & 22 & 13 \\
\hline & & Yes & 29 & 14 & 48 \\
\hline & Week 7 Engaged & No & 152 & 18 & 12 \\
\hline & & Yes & 46 & 18 & 39 \\
\hline \multirow[t]{4}{*}{ Week 9 (Quiz 2) } & Week 4 Engaged & No & 169 & 9 & 5 \\
\hline & & Yes & 29 & 5 & 17 \\
\hline & Week 6 Engaged & No & 152 & 6 & 4 \\
\hline & & Yes & 46 & 8 & 17 \\
\hline
\end{tabular}

feedback is the starting point of the continuous student support, as well as ongoing course improvement.

To summarise, the current paper applied a data-driven approach for improving feedback processes and narrowing the feedback gap. Putting all the results together, using CTAs in customised email messages has turned out to be a successful practice. This practice was well-received among students. It also allowed the researchers to explore students reactions to feedback messages quantitatively and discover patterns which can be used to design interventions and improve feedback recipience for students of different backgrounds. The current paper demonstrated that the popular and tried and true method of collecting data on actions on feedback messages applies to education and helps in understanding feedback recipience at a deeper level and narrowing the feedback gap.

\section{REFERENCES}

[1] I. Elaine Allen and Jeff Seaman. 2013. Changing Course: Ten Years of Tracking Online Education in the United States. Sloan Consortium, Newburyport, Massachusetts, US. https://eric.ed.gov/?id=ED541571

[2] Ryan S. Anderton, Tess Evans, and Paola T. Chivers. 2016. Predicting Academic Success of Health Science Students for First Year Anatomy and Physiology.
International Journal of Higher Education 5, 1 (2016), 250-260. https://doi.org/10. 5430/ijhe.v5n1p250

[3] Edd Applegate. 2005. Strategic copywriting: How to create effective advertising. Rowman \& Littlefield, Maryland, US.

[4] Sophie Arkoudis, Mollie Dollinger, Chi Baik, and Allan Patience. 2018. International students' experience in Australian higher education: can we do better? Higher Education 77 (2018), 799-813. https://doi.org/10.1007/s10734-018-0302-x

[5] Kimberly E. Arnold and Matthew D. Pistilli. 2012. Course Signals at Purdue: Using Learning Analytics to Increase Student Success. In Proceedings of the 2nd International Conference on Learning Analytics and Knowledge (LAK '12). ACM, New York, NY, USA, 267-270. https://doi.org/10.1145/2330601.2330666

[6] Suzanne E. Beech. 2018. Adapting to change in the higher education system: international student mobility as a migration industry. Fournal of Ethnic and Migration Studies 44, 4 (2018), 610-625. https://doi.org/10.1080/1369183X.2017. 1315515

[7] Robert A. Bjork, John Dunlosky, and Nate Kornell. 2013. Self-Regulated Learning: Beliefs, Techniques, and Illusions. Annual Review of Psychology 64, 1 (2013), 417-444. https://doi.org/10.1146/annurev-psych-113011-143823

[8] David Boud and Elizabeth Molloy. 2013. Feedback in higher and professional education: understanding it and doing it well. Routledge, New York, NY, USA.

[9] David Boud and Elizabeth Molloy. 2013. Rethinking models of feedback for learning: the challenge of design. Assessment \& Evaluation in Higher Education 38, 6 (2013), 698-712. https://doi.org/10.1080/02602938.2012.691462

[10] Tom Broos, Laurie Peeters, Katrien Verbert, Carolien Van Soom, Greet Langie, and Tinne De Laet. 2017. Dashboard for Actionable Feedback on Learning Skills: Scalability and Usefulness. In Learning and Collaboration Technologies. Technology 
in Education (Lecture Notes in Computer Science), Panayiotis Zaphiris and Andri Ioannou (Eds.). Springer International Publishing, Vancouver, Canada, 229-241.

[11] Deborah L. Butler and Philip H. Winne. 1995. Feedback and Self-Regulated Learning: A Theoretical Synthesis. Review of Educational Research 65, 3 (1995), 245-281. https://doi.org/10.3102/00346543065003245

[12] David Carless. 2015. Excellence in university assessment: Learning from awardwinning practice. Routledge, New York, NY, USA.

[13] David Carless. 2019. Feedback loops and the longer-term: towards feedback spirals. Assessment \& Evaluation in Higher Education 44, 5 (2019), 705-714. https://doi.org/10.1080/02602938.2018.1531108

[14] David Carless and David Boud. 2018. The development of student feedback literacy: enabling uptake of feedback. Assessment \& Evaluation in Higher Education 43, 8 (2018), 1315-1325. https://doi.org/10.1080/02602938.2018.1463354

[15] Linda Corrin and Paula de Barba. 2014. Exploring students' interpretation of feedback delivered through learning analytics dashboards. In Proceedings of the ASCILITE 2014 conference. Rhetoric and Reality: Critical perspectives on educational technology, Dunedin, NZ., 629-633.

[16] Linda Corrin and Paula De Barba. 2015. How do students interpret feedback delivered via dashboards?. In Proceedings of the fifth international conference on learning analytics and knowledge. ACM, Poughkeepsie, NY, USA, 430-431. https://doi.org/10.1145/2723576.2723662

[17] Phillip Dawson, Michael Henderson, Tracii Ryan, Paige Mahoney, David Boud, Michael Phillips, and Elizabeth Molloy. 2018. Technology and Feedback Design In Learning, Design, and Technology, Michael J Spector, Barbara B Lockee, and Marcus D. Childress (Eds.). Springer International Publishing, Cham, 1-45. https: //doi.org/10.1007/978-3-319-17727-4_124-1

[18] N. Dwyer and S. Marsh. 2016. How students regard trust in an elearning context. In 14th Annual Conference on Privacy, Security and Trust (PST). IEEE, Auckland, New Zealand, 682-685. https://doi.org/10.1109/PST.2016.7906956

[19] Carol Evans. 2013. Making Sense of Assessment Feedback in Higher Education. Review of Educational Research 83, 1 (2013), 70-120. https://doi.org/10.3102/ 0034654312474350

[20] Jerome Friedman, Trevor Hastie, and Robert Tibshirani. 2001. The elements of statistical learning. Vol. 1. Springer series in statistics New York, New York, NY, USA.

[21] Deanne Gannaway, Teegan Green, and Patricie Mertova. 2018. So how big is big? Investigating the impact of class size on ratings in student evaluation. Assessment \& Evaluation in Higher Education 43, 2 (2018), 175-184. https://doi.org/10.1080/ 02602938.2017.1317327

[22] Dragan Gašević, Shane Dawson, and George Siemens. 2015. Let's not forget: Learning analytics are about learning. TechTrends 59, 1 (2015), 64-71. https: //doi.org/10.1007/s11528-014-0822-x

[23] Graham Gibbs and Claire Simpson. 2005. Conditions under which assessment supports students' learning. Learning and teaching in higher education 1, 1 (2005), 3-31.

[24] Russell Glass and Sean Callahan. 2014. The Big Data-driven business: How to use big data to win customers, beat competitors, and boost profits. John Wiley \& Sons, Hoboken, New Jersey.

[25] Jeff Grann and Deborah Bushway. 2014. Competency Map: Visualizing Student Learning to Promote Student Success. In Proceedings of the Fourth International Conference on Learning Analytics And Knowledge (LAK '14). ACM, New York, NY, USA, 168-172. https://doi.org/10.1145/2567574.2567622

[26] Susan Gunelius. 2018. Ultimate Guide to Email Marketing for Business. Entrepreneur Press, Irvine.

[27] Richard C. Hanna, Scott D. Swain, and Jason Smith. 2015. Email Marketing in a Digital World: The Basics and Beyond. Business Expert Press, New York, United States.

[28] Mari Hartemo. 2016. Email marketing in the era of the empowered consumer Journal of Research in Interactive Marketing 10, 3 (2016), 212-230. https://doi org/10.1108/JRIM-06-2015-0040

[29] John Hattie. 1999. Influences on student learning. Inaugural lecture given on August 2 (1999), 1-25.

[30] John Hattie and Helen Timperley. 2007. The Power of Feedback. Review of Educational Research 77, 1 (2007), 81-112. https://doi.org/10.3102/003465430298487

[31] Christothea Herodotou, Sarah Heiser, and Bart Rienties. 2017. Implementing randomised control trials in open and distance learning: a feasibility study. Open Learning: The Journal of Open, Distance and e-Learning 32, 2 (2017), 147-162. https://doi.org/10.1080/02680513.2017.1316188

[32] Joel A. Howell, Lynne D. Roberts, and Vincent O. Mancini. 2018. Learning analytics messages: Impact of grade, sender, comparative information and message style on student affect and academic resilience. Computers in Human Behavior 89 (2018), 8-15. https://doi.org/10.1016/j.chb.2018.07.021

[33] Anders Jonsson. 2013. Facilitating productive use of feedback in higher education Active Learning in Higher Education 14, 1 (2013), 63-76. https://doi.org/10.1177/ 1469787412467125

[34] Frances Kay-Lambkin, Sallie-Anne Pearson, and Isobel Rolfe. 2002. The influence of admissions variables on first year medical school performance: a study from Newcastle University, Australia. Medical Education 36, 2 (2002), 154-159. https: //doi.org/10.1046/j.1365-2923.2002.01071.x

[35] Rene Kizilcec and Christopher Brooks. 2017. Diverse Big Data and Randomized Field Experiments in Massive Open Online Courses. In The Handbook of Learning
Analytics (1 ed.), Charles Lang, George Siemens, Alyssa Friend Wise, and Dragan Gaševic (Eds.). Society for Learning Analytics Research (SoLAR), Alberta, Canada, 211-222. http://solaresearch.org/hla-17/hla17-chapter1

[36] Avraham N Kluger and Angelo DeNisi. 1996. The effects of feedback interventions on performance: A historical review, a meta-analysis, and a preliminary feedback intervention theory. Psychological bulletin 119, 2 (1996), 254-284. https://doi. org/10.1037/0033-2909.119.2.254

[37] Markus Krause, Marc Mogalle, Henning Pohl, and Joseph Jay Williams. 2015. A playful game changer: Fostering student retention in online education with social gamification. In Proceedings of the Second (2015) ACM Conference on Learning@ Scale. ACM, Vancouver, BC, Canada, 95-102. https://doi.org/10.1145/2724660. 2724665

[38] Alan B Krueger. 1999. Experimental estimates of education production functions. The quarterly journal of economics 114, 2 (1999), 497-532. https://doi.org/10.1162/ 003355399556052

[39] Franki Y. H. Kung and Abigail Scholer. 2018. Message Framing Influences Perceptions of Feedback (In)directness. Social Cognition 36, 6 (2018), 626-670. https://doi.org/10.1521/soco.2018.36.6.626

[40] Anne Lacey and Donna Luff. 2001. Qualitative data analysis. Trent Focus Sheffield, Nottingham.

[41] Lisa-Angelique Lim, Sheridan Gentili, Abelardo Pardo, Vitomir Kovanović, Alexander Whitelock-Wainwright, Dragan Gašević, and Shane Dawson. 2019. What changes, and for whom? A study of the impact of learning analyticsbased process feedback in a large course. Learning and Instruction (2019), 1-11. https://doi.org/10.1016/j.learninstruc.2019.04.003

[42] Danny Yen-Ting Liu, Kathryn Bartimote-Aufflick, Abelardo Pardo, and Adam J Bridgeman. 2017. Data-Driven Personalization of Student Learning Support in Higher Education. Learning Analytics: Fundaments, Applications, and Trends 94 (2017), 143-169. https://doi.org/10.1007/978-3-319-52977-6_5

[43] Phil Long and George Siemens. 2011. Penetrating the Fog: Analytics in Learning and Education. EDUCAUSE Review 46, 5 (2011), 30-40. https://doi.org/10.17471/ 2499-4324/195

[44] Tim McKay, Kate Miller, and Jared Tritz. 2012. What to Do with Actionable Intelligence: E2Coach As an Intervention Engine. In Proceedings of the 2nd International Conference on Learning Analytics and Knowledge (LAK '12). ACM, Vancouver, British Columbia, Canada, 88-91. https://doi.org/10.1145/2330601.2330627

[45] Kirsten McKenzie and Robert Schweitzer. 2001. Who Succeeds at University? Factors predicting academic performance in first year Australian university students. Higher Education Research \& Development 20, 1 (2001), 21-33. https: //doi.org/10.1080/07924360120043621

[46] Moodle. 2019. URL resource - MoodleDocs. https://docs.moodle.org/37/en/URL resource

[47] David Nicol. 2010. From monologue to dialogue: improving written feedback processes in mass higher education. Assessment \& Evaluation in Higher Education 35, 5 (2010), 501-517. https://doi.org/10.1080/02602931003786559

[48] David Nicol and Debra Macfarlane-Dick. 2006. Formative assessment and self-regulated learning: a model and seven principles of good feedback practice. Studies in Higher Education 31, 2 (2006), 199-218. https://doi.org/10.1080/ 03075070600572090

[49] Abelardo Pardo, Kathryn Bartimote, Simon Buckingham Shum, Shane Dawson, Jing Gao, Dragan Gašević, Steve Leichtweis, Danny Liu, Roberto MartínezMaldonado, Negin Mirriahi, Adon Christian Michael Moskal, Jurgen Schulte, George Siemens, and Lorenzo Vigentini. 2018. OnTask: Delivering Data-Informed, Personalized Learning Support Actions. fournal of Learning Analytics 5, 3 (2018), 235-249. https://doi.org/10.18608/jla.2018.53.15

[50] Abelardo Pardo, Jelena Jovanovic, Shane Dawson, Dragan Gašević, and Negin Mirriahi. 2019. Using learning analytics to scale the provision of personalised feedback. British fournal of Educational Technology 50, 1 (2019), 128-138. https: //doi.org/10.1111/bjet.12592

[51] Ji-Hye Park and Hee Jun Choi. 2009. Factors influencing adult learners' decision to drop out or persist in online learning. Fournal of Educational Technology \& Society 12, 4 (2009), 207-217. https://doi.org/10.1016/S0022-4359(00)00035-X

[52] Amy L. Parsons and Elzbieta Lepkowska-White. 2010. Web Site References in Print Advertising: An Analysis of Calls to Action. Fournal of Internet Commerce 9, 3-4 (2010), 151-163. https://doi.org/10.1080/15332861.2010.526487

[53] Ernest T Pascarella, Gregory Wolniak, TM Cruce, TA Seifert, and Charles F Blaich. 2005. Liberal arts colleges and liberal arts education: New evidence of impacts. ASHE Higher Education Report. ASHE, San Francisco, California.

[54] Edd Pitt and Lin Norton. 2017. 'Now that's the feedback I want!' Students' reactions to feedback on graded work and what they do with it. Assessment \& Evaluation in Higher Education 42, 4 (2017), 499-516. https://doi.org/10.1080/ 02602938.2016.1142500

[55] Margaret Price, Karen Handley, Jill Millar, and Berry O'Donovan. 2010. Feedback: all that effort, but what is the effect? Assessment \& Evaluation in Higher Education 35, 3 (2010), 277-289. https://doi.org/10.1080/02602930903541007

[56] Xavier Robin, Natacha Turck, Alexandre Hainard, Natalia Tiberti, Frédérique Lisacek, Jean-Charles Sanchez, and Markus Müller. 2011. pROC: an open-source package for $\mathrm{R}$ and $\mathrm{S}+$ to analyze and compare ROC curves. BMC bioinformatics 12, 1 (2011), 77. https://doi.org/10.1186/1471-2105-12-77 
[57] Anna D. Rowe. 2017. Feelings About Feedback: The Role of Emotions in Assessment for Learning. In Scaling up Assessment for Learning in Higher Education, David Carless, Susan M. Bridges, Cecilia Ka Yuk Chan, and Rick Glofcheski (Eds.). Springer Singapore, Singapore, 159-172. https://doi.org/10 1007/978-981-10-3045-1_11

[58] Anna D. Rowe and Leigh N. Wood. 2009. Student Perceptions and Preferences for Feedback. Asian Social Science 4, 3 (2009), 78-88. https://doi.org/10.5539/ass. v4n 3 p 78

[59] Tracii Ryan, Dragan Gašević, and Michael Henderson. 2019. Identifying the Impact of Feedback Over Time and at Scale: Opportunities for Learning Analytics. In The Impact of Feedback in Higher Education: Improving Assessment Outcomes for Learners, Michael Henderson, Rola Ajjawi, David Boud, and Elizabeth Molloy (Eds.). Springer International Publishing, Cham, 207-223. https://doi.org/10 1007/978-3-030-25112-3 12

[60] Navdeep S. Sahni, S. Christian Wheeler, and Pradeep Chintagunta. 2018. Person alization in Email Marketing: The Role of Noninformative Advertising Content Marketing Science 37, 2 (2018), 236-258. https://doi.org/10.1287/mksc. 2017.1066

[61] Michael Sheard. 2009. Hardiness commitment, gender, and age differentiate university academic performance. British fournal of Educational Psychology 79, 1 (2009), 189-204. https://doi.org/10.1348/000709908X304406

[62] Valerie J. Shute. 2008. Focus on Formative Feedback. Review of Educational Research 78, 1 (2008), 153-189. https://doi.org/10.3102/0034654307313795

[63] Gyanendra Singh, Himanshu Singh, and Sonika Shriwastav. 2019. Improving Email Marketing Campaign Success Rate Using Personalization. In Advances in Analytics and Applications, Arnab Kumar Laha (Ed.). Springer Singapore, Singapore, 77-83. https://doi.org/10.1007/978-981-13-1208-3_8

[64] David M. Szymanski and Richard T. Hise. 2000. E-satisfaction: an initial examination. Fournal of Retailing 76, 3 (2000), 309-322. https://doi.org/10.1016/ S0022-4359(00)00035-X

[65] R Core Team. 2019. R: A Language and Environment for Statistical Computing. https://www.R-project.org/

[66] Stephanie D. Teasley. 2017. Student Facing Dashboards: One Size Fits All? Technology, Knowledge and Learning 22, 3 (2017), 377-384. https://doi.org/10.1007/ s10758-017-9314-3

[67] Dirk Tempelaar, Bart Rienties, Jenna Mittelmeier, and Quan Nguyen. 2018. Student profiling in a dispositional learning analytics application using formative assessment. Computers in Human Behavior 78 (2018), 408-420. https //doi.org/10.1016/j.chb.2017.08.010

[68] Sebastian Thomas. 2010. The Influence of the Tone of Feedback Prompts on the Learning Behavior and Satisfaction of University Students in a Multiple Cue Probablility Learning Task. Master's thesis. Rice University, United States - Texas. http //search.proquest.com/docview/881649904/abstract/67EEC4A3E71543F4PQ/1

[69] Sebastian Thomas. 2013. The impact of Feedback Tone, Grammatical Person and Presentation Mode on Performance and Preference in a Computer-based Learning
Task. Thesis. School of Social Sciences. https://scholarship.rice.edu/handle/1911 72050

[70] Gill Turner and Graham Gibbs. 2010. Are assessment environments gendered? An analysis of the learning responses of male and female students to different assessment environments. Assessment \& Evaluation in Higher Education 35, 6 (2010), 687-698. https://doi.org/10.1080/02602930902977723

[71] Charalambos Vrasidas and Marina Stock McIsaac. 1999. Factors influencing interaction in an online course. American fournal of Distance Education 13, 3 (1999), 22-36. https://doi.org/10.1080/08923649909527033

[72] Philip H. Winne and Allyson F. Hadwin. 1998. Studying as self-regulated learning In Metacognition in educational theory and practice. Lawrence Erlbaum Associates Publishers, Mahwah, NJ, US, 277-304.

[73] Naomi E. Winstone and Robert Nash. 2016. The "Developing Engagement with Feedback Toolkit (DEFT)": Integrating Assessment Literacy into Course Design. Technical Report. Higher Education Academy. 48 pages. https://www.heacademy.ac.uk/system/files/resources/the developing engagement with feedback toolkit deft 0.pdf

[74] Naomi E. Winstone, Robert A. Nash, Michael Parker, and James Rowntree. 2017. Supporting Learners' Agentic Engagement With Feedback: A Systematic Review and a Taxonomy of Recipience Processes. Educational Psychologist 52, 1 (2017), 17-37. https://doi.org/10.1080/00461520.2016.1207538

[75] Naomi E. Winstone, Robert A. Nash, James Rowntree, and Richard Menezes. 2016. What do students want most from written feedback information? Distinguishing necessities from luxuries using a budgeting methodology. Assessment \& Evaluation in Higher Education 41, 8 (2016), 1237-1253. https: //doi.org/10.1080/02602938.2015.1075956

[76] Naomi E. Winstone, Robert A. Nash, James Rowntree, and Michael Parker. 2017. 'It'd be useful, but I wouldn't use it': barriers to university students' feedback seeking and recipience. Studies in Higher Education 42, 11 (2017), 2026-2041. https://doi.org/10.1080/03075079.2015.1130032

[77] Carol Withey. 2013. Feedback engagement: forcing feed-forward amongst law students. The Law Teacher 47, 3 (2013), 319-344. https://doi.org/10.1080/03069400. 2013.851336

[78] B. T. M. Wong and K. C. Li. 2018. Learning Analytics Intervention: A Review of Case Studies. In 2018 International Symposium on Educational Technology (ISET). IEEE Osaka, Japan, 178-182. https://doi.oro/10.1109/ISET 2018.00047

[79] Gerald Wurf and Lindy Croft-Piggin. 2015. Predicting the academic achievement of first-year, pre-service teachers: the role of engagement, motivation, ATAR, and emotional intelligence. Asia-Pacific Journal of Teacher Education 43, 1 (2015), 75-91. https://doi.org/10.1080/1359866X.2014.932328

[80] Xi (Alan) Zhang, V. Kumar, and Koray Cosguner. 2017. Dynamically Managing a Profitable Email Marketing Program. Journal of Marketing Research 54, 6 (2017), 851-866. https://doi.org/10.1509/jmr.16.0210 